EXTENDED REPORT

\title{
Determinants of surgery related anxiety in cataract patients
}

\author{
M D Nijkamp, C A Kenens, A J M Dijker, R A C Ruiter, F Hiddema, R M M A Nuijts
}

Br J Ophthalmol 2004;88:1310-1314. doi: 10.1136/bjo.2003.037788

\begin{abstract}
See end of article for authors' affiliations

authors................

Correspondence to: M D Nijkamp, PhD Department of Health Education and Promotion Maastricht University, PO Box 616, 6200 MD Maastricht, Netherlands; M.Nijkamp@GVO. unimaas.nl

Accepted for publication 1 February 2004
\end{abstract}

\begin{abstract}
Background/aims: Not much is known about the relative importance of different determinants of anxiety in cataract patients. This study analysed the predictive value of factors related to surgery induced anxiety. Methods: In 128 cataract patients, recruited from two hospitals (Medical Centre Maastricht Annadal (MCMA) and Rotterdam Eye Hospital (REH)), state anxiety was assessed at four different time points using the State-Trait Anxiety Inventory (STAl). The following predictive factors of anxiety were measured: trait anxiety, outcome expectancies, doctor-patient relationship, coping strategy, social support, information supply, sociodemographic variables, and previous cataract surgery. Repeated measures ANOVA, $t$ tests, multiple regression analysis, and correlations were used to analyse data.

Results: In general patients reported little anxiety. The level of anxiety (scale 1-4) was the highest before surgery, decreased immediately after surgery, and increased again after the postoperative visit. Patients with higher trait anxiety levels $(r=0.41 ; p<0.01)$, and women $(r=0.30 ; p<0.01)$ reported more anxiety. The REH patients showed lower anxiety scores than the MCMA patients.

Conclusion: Women and patients with higher trait anxiety were more likely to experience higher levels of state anxiety. Positive outcome expectancies and social support may decrease anxiety.
\end{abstract}

A nxiety is an emotion that can be divided into two dimensions: state and trait anxiety. ${ }^{1}$ State anxiety is specifically triggered by a threatening situation and fluctuates over time. Trait anxiety is a stable natural anxiety disposition, and may influence the state anxiety levels experienced during anxiety provoking situations. Anxiety in surgical patients is highly acknowledged. ${ }^{2}$ Former studies indicated that cataract patients can experience anxiety preoperatively, peroperatively, and postoperatively. ${ }^{3-5}$ In a preceding qualitative study, ${ }^{5}$ a model describing personal and situational determinants of anxiety in patients awaiting cataract surgery was suggested (fig 1).

The personal determinants of the model are based on the cognitive appraisal model, which states that patients can use different coping strategies to deal with upcoming surgery that depend on their appraisals - that is, outcome expectancies. ${ }^{6}$ The coping strategies, in turn, may influence the level of anxiety. ${ }^{7}$ With respect to situational factors, it seems that a good doctor-patient relationship, social support, and patient education can decrease anxiety among patients. ${ }^{89} 9$ Furthermore, former studies suggested that music and visual sensations perceived during surgery may influence anxiety in cataract patients. ${ }^{10-12}$ Additionally, our preceding study showed that retrobulbar anaesthesia which is used in cataract surgery may cause anxiety, and that previous experience influenced patient's anxiety during the preoperative, peroperative, and postoperative stages of their second surgery. ${ }^{513-15}$ Demographic variables like age, sex, and education may also influence anxiety, women especially seem to report higher anxiety levels. ${ }^{1}$

To our knowledge, no quantitative study has yet been performed that combined these variables in a single study, and tested their relations with anxiety before, during, and after cataract surgery. The aim of this study is to indicate the factors that are related to cataract surgery induced anxiety. Results of this study provide recommendations for future programmes to reduce anxiety regarding one of the most frequently performed surgical procedures (about 90000 surgeries a year in the Netherlands, www.rivm.nl).

\section{PATIENTS AND METHODS \\ Patients}

This study was carried out among 128 cataract patients who had routine cataract surgery with intraocular lens implantation in the period from June to September 2001 at the Medical Centre Maastricht Annadal (MCMA, $\mathrm{n}=50$ ) or the Rotterdam Eye Hospital (REH, $n=78$ ). The medical ethics committee approved the research proposal, and all patients signed an informed consent before inclusion in the study. Patients were selected according to the following inclusion criteria: with from cataract and suitable for outpatient surgery. Exclusion criteria were ocular co-morbidity, dementia, psychological disorders, and not being able to speak or read Dutch. The mean age of the patients was 73.2 (SD 8.6) years (range $50-89$ years); 58\% were women and $42 \%$ men. Most patients $(79 \%)$ were categorised as low or medium educated. Fifty three $(41 \%)$ patients reported previous cataract surgery on the fellow eye. Except for age (MCMA 75.4 (SD 6.9) years and REH 71.9 (9.3) years; $p<0.05$ ), there were no significant differences in patient characteristics between the two hospitals (table 1). Four patients were lost to follow up during the study, because of refusal of further participation $(\mathrm{n}=3)$, and too much difficulty with answering the questions $(n=1)$. Their completed questionnaires were used for analyses.

\section{Surgical technique}

Cataract surgeons at both hospitals performed standard phacoemulsification with monofocal intraocular lens implantation and retrobulbar anaesthesia. Patients at the REH received $7.5 \mathrm{mg}$ Dormicum (Roche, Netherlands) before local anaesthesia, unlike patients at the MCMA.

\section{Data gathering}

Patients were followed during the entire healthcare process, and were asked to complete four different questionnaires at the hospital at four different points in time. The first questionnaire was administered immediately after the last preoperative visit 1 or 2 weeks before cataract surgery $(\mathrm{tl})$. The second questionnaire was handed out a couple of minutes before surgery; at the MCMA before the retrobulbar 


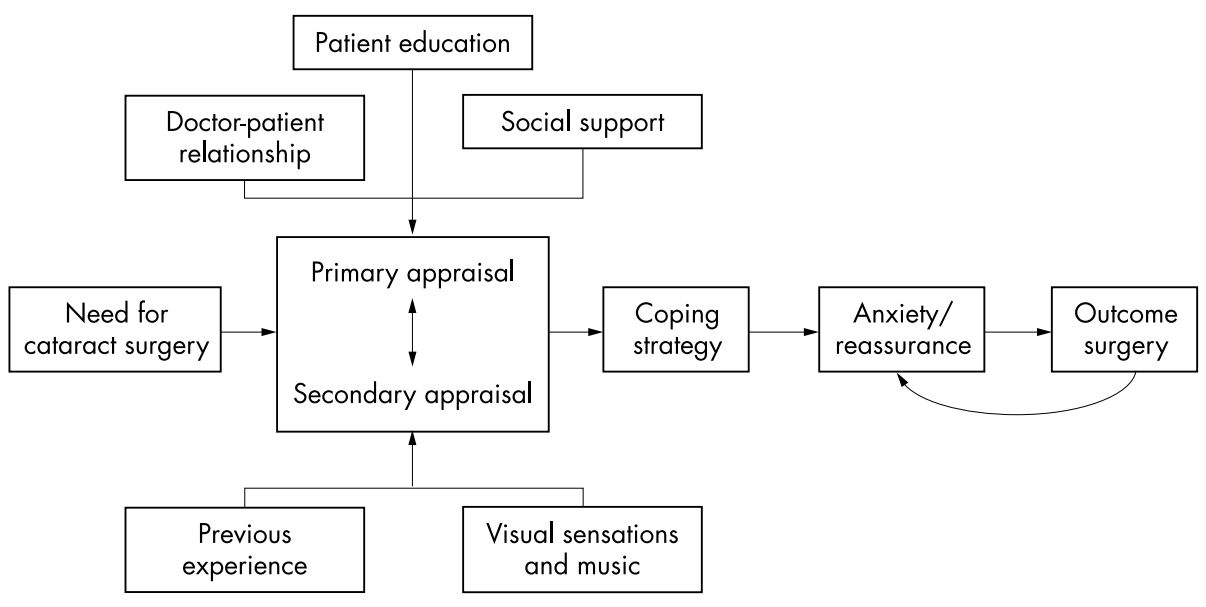

Figure 1 Research model of anxiety related factors is based upon Nijkamp et al. block, and at the REH before sedatives were given (t2). Patients were asked to complete the third questionnaire immediately after surgery ( $\mathrm{t} 3)$. The last questionnaire was administered the day after surgery (t4). Questionnaires 1 and 4 took approximately 20 minutes for patients to complete, while questionnaires 2 and 3 took about 1 minute.

\section{Materials}

Most questions in the four questionnaires could be answered on four point scales varying from "No!" (1), "Not really" (2), "On the whole, yes" (3) to "Yes!" (4). ${ }^{16}$ On all scales, a higher score indicated a higher level of the factor measured. Anxiety was measured by the shortened Dutch version of the Spielberger State-Trait Anxiety Inventory (STAI), which distinguishes between state anxiety and trait anxiety and has shown good validity. ${ }^{17}{ }^{18}$ State anxiety was measured by all four questionnaires, while trait anxiety was measured only by the first questionnaire, because it is assumed to be a stable factor over time. ${ }^{.}$The variable "outcome expectancy" was measured by a three item scale at $\mathrm{t} l$. The "doctor-patient relationship" was measured by a three item scale at $\mathrm{tl}$, and a 14 item scale at $\mathrm{t} 4$, including questions like "The ophthalmologist treated me in a reassuring way." The Utrecht Coping List (UCL), which has proved to be a valid and reliable instrument, measured "coping strategy" at tl. ${ }^{19} 20$ Patients were asked how often they used the specific coping strategies (that is, problem based or emotional coping): "seldom or never," "sometimes," "often," and "almost always." Social support (tl) was measured on a seven item scale and included questions like "I can talk about my feelings with regard to cataract surgery with people in my social environment." Information supply (t4) was measured by 20 questions about various aspects of cataract-for example, questions concerning information about the risks of treatment. Patients were asked whether they received the information at all, and whether they understood this information. Moreover, five questions about music during surgery and perceived visual sensations were asked. At tl patients could rate to what extent they felt anxious about the retrobulbar anaesthesia. Finally, a few open ended questions addressing what patients found most reassuring and fear arousing were included. At the REH, audiovisual patient education (that is, a live surgery video report) is presented in addition to oral/written information as given at the MCMA. Therefore, the REH patients were asked to answer a few additional questions (t4).

The questionnaires 1 and 4 were pilot tested at both hospitals among 18 cataract patients before onset of the study. Cronbach's alpha was used to calculate the internal consistency of the scales and showed satisfactory values, varying from 0.70 to 0.87 .

\section{Statistical analysis}

Data analyses were performed using SPSS 10.0 (SPSS Inc, Chicago, IL, USA). Before the main analyses were carried out, data were screened and recoded. Repeated measures analysis of variance (RM ANOVA) was used to show differences in levels of anxiety over time between hospitals.

Independent and paired $t$ tests showed differences between groups and between times of measurement. Multiple linear regression analysis (ENTER method) was used to indicate the relative importance of separate variables in predicting anxiety. Both Pearson correlations and regression coefficients were calculated for mean anxiety levels across the four measurement points. Patients who had peroperative or postoperative complications $(n=6)$ were excluded from

\begin{tabular}{|c|c|c|c|c|}
\hline \multirow[b]{2}{*}{ Variable } & \multicolumn{2}{|l|}{ Setting } & \multirow[b]{2}{*}{ All patients } & \multirow[b]{2}{*}{$p$ Value } \\
\hline & MCMA & REH & & \\
\hline Age, mean (SD) & $75.4(6.9)$ & $71.9(9.3)$ & $73.2(8.6)$ & $<0.05$ \\
\hline Sex, No (\%) & & & & 0.44 \\
\hline Male & $19(38)$ & $35(45)$ & $54(42)$ & \\
\hline Female & $31(62)$ & $43(55)$ & $74(58)$ & \\
\hline Education, No (\%) & & & & 0.69 \\
\hline Low & $24(49.0)$ & $31(40.3)$ & $55(43.7)$ & \\
\hline Middle & $16(32.7)$ & $28(36.4)$ & $44(34.9)$ & \\
\hline High & $9(18.3)$ & $18(23.4)$ & $27(21.4)$ & \\
\hline 2nd eye surgery*, No (\%) & $21(42.0)$ & $32(41.0)$ & $53(41.4)$ & 0.91 \\
\hline
\end{tabular}




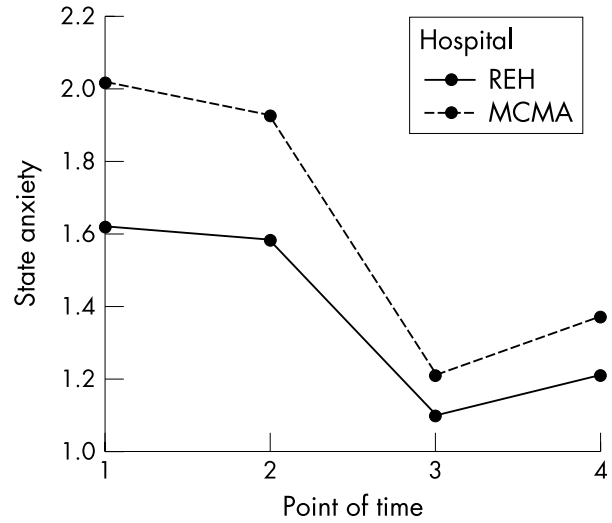

Figure 2 Mean anxiety scores per measurement point and per hospital.

postoperative analyses, because complications may affect the level of anxiety.

\section{RESULTS}

Mean reported levels of state anxiety at the four time points were $1.8(\mathrm{SD} 0.81)(\mathrm{t} 1), 1.8(0.75)(\mathrm{t} 2), 1.1(0.34)(\mathrm{t} 3)$, and $1.3(0.48)(\mathrm{t} 4)$, respectively. A RM ANOVA with state anxiety as within subjects factor and hospital site as between subjects factor showed a main effect of state anxiety over time $(p<0.01)$. Paired samples $t$ tests showed across hospital sites that state anxiety levels decreased immediately after surgery (t3) compared to the measure at $t 2(p<0.001)$, and increased again the day after surgery $(\mathrm{p}<0.001$, fig 2$)$.

Although the main effect of hospital site was significant for state anxiety $(p<0.01)$, no statistical support was found for the interaction between state anxiety and hospital site $(p=0.07)$. This finding indicates a similar course in time of anxiety for both settings. Trait anxiety did not differ between the two hospitals $(p=0.66)$, nor between male and female patients $(p=0.26)$. Anxiety specifically related to local anaesthesia (mean $1.97(1.18)$ ) also showed no difference between the two settings $(p=0.39)$. Table 2 shows the correlations between state anxiety at $\mathrm{t} 2$ and the hypothesised determinants, and the standardised regression weights of these determinants in predicting state anxiety at $\mathrm{t} 2$. Variables correlating significantly $(\mathrm{p}<0.05)$ with state anxiety were trait anxiety, outcome expectancy, social support, sex, and hospital. Multiple linear regression analysis showed that trait anxiety, sex, and hospital had the most predictive influence on state anxiety, explaining $36.9 \%$ of the variance. Patients with higher trait anxiety scores, women, and MCMA patients reported higher state anxiety scores.

There was no difference in anxiety immediately after surgery between patients who listened to music during surgery and those who did not $(\mathrm{p}=0.37)$. During surgery, 52 patients $(44 \%)$ perceived photopic phenomena like colours, light, and hands. Five of these patients (9.6\%) experienced this as threatening. In response to the open ended question asking what patients believed to be the most anxiety arousing; local anaesthesia, the unknown, and failure of surgery were mentioned. What patients found most reassuring were patient education, the expertise and welcome of the ophthalmologist and assisting personnel, a quiet and restful atmosphere, Dormicum sedation, and to be accompanied by a relative/acquaintance during the visits at the hospital. At the REH, 54\% of all patients watched the live cataract surgery video just before onset of surgery. Compared with patients who did not watch this video preoperatively, no difference was found in preoperative and postoperative anxiety levels (immediately before surgery $\mathrm{p}=0.93$; immediately after surgery $\mathrm{p}=0.93$ ). The live video was appraised as reassuring by $49 \%$ of all patients, $17 \%$ scored "not really."

\section{DISCUSSION}

The average patient experienced little anxiety related to cataract surgery (mean 1.5 (SD 0.48)). Patients reported highest levels of anxiety preoperatively. Immediately after surgery, the level of anxiety dropped, probably because of the relief. These results agree with research by Foggitt. ${ }^{4}$ The next day anxiety increased, which may be provoked by new concerns regarding what to do and expect. ${ }^{5}$ This finding emphasises the need for postoperative counselling by the ophthalmologist. It remains unclear compared to former studies $^{13-15}$ why differences in anxiety related to anaesthesia did not exist between hospitals in advance of the retrobulbar block; keeping in mind that REH patients could anticipate sedation before local anaesthesia. To obtain a greater reduction of anxiety during the days before surgery, patients should be better informed about the calming effects of Dormicum. To our knowledge no reference data are published with respect to STAI scores, which limits the possibility to assess the representativeness of our study. Corresponding with literature on STAI studies, trait anxiety also seemed to be an important determinant of state anxiety among cataract patients. ${ }^{21}$ Specifically, patients with higher trait anxiety levels showed increased state anxiety levels. Higher trait levels were found among women in those

Table 2 Determinants of state anxiety* in cataract patients

\begin{tabular}{lll}
\hline Determinant & $\begin{array}{l}\text { Pearson } \\
\text { correlation }\end{array}$ & $\begin{array}{l}\text { Standardised regression } \\
\text { coefficient }\end{array}$ \\
\hline Age & 0.004 & -0.025 \\
Sex & $0.300 \ddagger$ & $0.243 \ddagger$ \\
Education & -0.030 & 0.131 \\
2nd eye surgery & -0.100 & -0.076 \\
Hospital & $0.237 \ddagger$ & $0.305 \ddagger$ \\
Trait anxiety & $0.410 \ddagger$ & $0.381 \ddagger$ \\
Outcome expectancy & $-0.221 \dagger$ & -0.007 \\
Doctor-patient relationship & -0.166 & -0.059 \\
Problem based coping & -0.012 & 0.021 \\
Denial coping & 0.089 & -0.034 \\
Emotional coping & 0.119 & 0.043 \\
Social support & $-0.265 \ddagger$ & -0.075 \\
Information supply & -0.158 & -0.061 \\
$\mathrm{R}^{2}$ (explained variance) & & 0.369 \\
\hline
\end{tabular}

*State anxiety at $\mathrm{t} 2$.

†Significant at the 0.05 level.

$\ddagger$ Significant at the 0.01 level. 
studies, although we could not support that in our study. As expected, patients with higher outcome expectancies reported lower state anxiety levels. Unlike expected, the doctor-patient relationship was not identified as a determinant of state anxiety, which was paradoxically mentioned as a runner up reason for the most reassuring aspect. Surprisingly, coping strategy was also not related to anxiety. This may be a result of the expressed difficulties patients had in answering these questions. Questions were raised about the usefulness of coping measurements by means of checklists before surgery. ${ }^{22}$

Although the overall information supply did not show a significant correlation with anxiety, patients marked information most frequently as being the most reassuring. Morrell showed that structured preoperative teaching reduces anxiety in cataract patients, especially information regarding safety of cataract surgery. ${ }^{23}$ Other studies focusing on patient education showed rather low levels of knowledge with respect to cataract, and misperceptions in cataract patients who needed surgery, in addition to limited information retention. ${ }^{24-26}$ Those poor information retention percentages were related to advanced age and lower educational level. ${ }^{26}$ This may have led to the non-significance between the mean information score and state anxiety in our study.

In accordance with former studies, music did not influence anxiety levels. ${ }^{10}{ }^{12}$ As reported before, most visual sensations during cataract surgery do not appear to be very frightening. ${ }^{27}$ However, patient education should include information about visual perception during the procedure relieving the patients of unnecessary distress. Although not significant, patients undergoing their second cataract surgery reported less anxiety preoperatively, but postoperatively they reported more anxiety compared to first eye surgery patients. This was also found by Foggitt, and may be explained by the fact that not a single cataract surgery is performed in exactly the same way; so things are not always going as expected, which could increase feelings of anxiety. ${ }^{5}$ Age and education showed no relation to state anxiety, while sex was shown to be an important determinant. In accordance with former studies women experienced higher state anxiety levels than men. ${ }^{21}$

The analyses of this study showed that hospital setting is an important determinant of reported levels of state anxiety. Future research should therefore illustrate which specific hospital characteristics are predictive of differences in anxiety between the settings. Maybe information about complications differed between the two hospitals, which may induce these differences in reported state anxiety. Another explanation may be that the Rotterdam patients are more reserved in expressing their surgery related fear than the patients from Maastricht, which would indicate regional differences in expressing emotions. However, no data are available to confirm or reject this hypothesis.

The possibility that patients reported low state anxiety levels may be affected by artefacts (for example, social desirability). These should temper a conclusion that patients are not very anxious about cataract surgery, although measurements were taken to prevent these artefacts (for example, guaranteed anonymity). In addition, it may not be useful to attempt to reduce anxiety completely, because a low level of anxiety can be beneficial by promoting effective preparation and accurate expectations of discomfort, and thus preventing disappointment. ${ }^{28}$

In conclusion, to decrease anxiety, more emphasis should be focused on reassuring determinants by paying more attention to outcome expectancies and social support, especially for women and patients with a noticeably higher trait anxiety levels. The routine aspect of cataract surgery may be emphasised to increase positive outcome expectancies. Furthermore, patients should be recommended to bring relatives or friends with them during hospital visits for social support.

\section{ACKNOWLEDGEMENTS}

We thank Anne Lems and Marijke Roeling for their contribution to this study.

\section{Authors' affiliations}

M D Nijkamp, C A Kenens, A J M Dijker, Maastricht University, Department of Health Education and Promotion, Netherlands M D Nijkamp, Eye Research Institute Maastricht (ERIM), Netherlands M D Nijkamp, A J M Dijker, R A C Ruiter, The Care and Public Health Research Institute (CAPHRI), Netherlands

R A C Ruiter, Maastricht University, Department of Experimental Psychology, Netherlands

F Hiddema, Rotterdam Eye Hospital, Rotterdam, Netherlands R M M A Nuijts, University Hospital Maastricht, Department of Ophthalmology, Maastricht, Netherlands

\section{REFERENCES}

1 Spielberger CD. Manual for the State-Trait Anxiety Inventory. Palo Alto, CA: Consulting Psychologists Press Inc, 1970

2 Breemhaar B, van den Borne HW, Mullen PD. Inadequacies of surgical patient education. Patient Education and Counseling 1996;28:31-4.

3 Fagerström R. Fear of a cataract operation in aged persons. Psychol Rep 1993; 72:1339-46.

4 Foggitt PS. Anxiety in cataract surgery: pilot study. J Cataract Refract Surg 2001; 27:1651-5.

5 Niikamp MD, Ruiter RAC, Roeling $M$, et al. Factors related to fear in patients undergoing cataract surgery: a qualitative study focusing factors associated with the fear and reassurance among patients who need to undergo cataract surgery. Patient Education \& Counseling 2002;47:265-72.

6 Cohen F, Lazarus RS. Coping and adaptation in health and illness. In: Mechanic D, ed. Handbook of health, health care and the health professions. London: The Free Press, 1983:608-35.

7 Taylor SE. Health psychology, 3rd ed. New York: McGraw-Hill, 1995:2258.

8 Visser APh. Angst en patiëntenvoorlichting. In: Damoiseaux V, Visser APh, eds. Patiëntenvoorlichting, een interdisciplinaire benadering. Assen: van Gorcum, 1988:225-43.

9 Gerdes EP, Guidi EJ. Anxiety in patients awaiting primary medical care. Med Care 1987;25:913-23.

10 Allen K, Golden LH, Izzo Jr JL, et al. Normalization of hypertensive responses during ambulatory surgical stress by perioperative music. Psychosom Med 2001;63:487-92.

11 Au Eong KG, Lim TH, Lee HM, et al. Subjective visual experience during phacoemulsification and intraoculair lens implantation using retrobulbar anesthesia. J Cataract Refract Surg 2000;26:842-6.

12 Cruise CJ, Chung F, Yogendran S, et al. Music increases satisfaction in elderly outpatients undergoing cataract surgery. Can J Anaesth 1997;44:43-8.

13 Kiefer RT, Weindler J, Ruprecht, KW. Oral low-dose midazolam as premedication for intraoculair surgery in retrobulbar anesthesia: cardiovasculair effects and relief of perioperative anxiety. Eur J Ophthalmol 1997;7:185-92.

14 Weindler J, Mohamed G, Lieblang S, et al. Perioperative physiological and cognitive functions following oral premedication with $3.75 \mathrm{mg}$ midazolam in operations with retrobulbair anesthesia. Anaesthesist 1996;45:826-33.

15 Janzen PR, Christys A, Vucevic M. Patient-controlled sedation using propofol in elderly patients in day-case cataract surgery. Br J Anaesth 1999;82:635-6.

16 Sixma HJ, Campan van C, Kerssens JJ, et al. Onderzoeksprogramma Kwaliteit van Zorg. De QUOTE-vragenlijsten. Kwaliteit van zorg vanuit patiëntenperspectief; vier nieuwe vragenlijsten. Utrecht: NIVEL, 1998;27.

17 Ploeg van der HM, Defares PB, Spielberger CD. Handleiding bij de ZelfBeoordelings Vragenlijst ZBV. Een Nederlandstalige bewerking van de Spielberger State-Trait Anxiety Inventory STAI-DY. Lisse: Swets en Zeitlinger, 1980.

18 Marteau TM, Bekker $\mathrm{H}$. The development of a six-item short-form of the Spielberger State-Trait Anxiety Inventory (STAI). Br J Clin Psychol 1992;31:301-6.

19 Schreurs PJG, Van de Willige G, Brosschot JF, et al. De Utrechtse Copinglijst: UCL. Omgaan met problemen en gebeurtenissen. Lisse: Swets \& Zeitlinger, 1993.

20 Sanderman R, Ormel J. De Utrechtse Copingliist (UCL): validiteit en betrouwbaarheid. Gedrag en Gezondheid 1992;20:32-7.

21 Spielberger CD. State-Trait Inventory (STAl). In: Furer JW, König-Zahn C, Tax $B$, eds. Het meten van de gezondheidstoestand. Beschrijving en evaluatie van vragenlijsten. Assen: Van Gorcum, 1995.

22 Coyne JC, Gottlieb BH. The mismeasure of coping by checklist. J Pers 1996;64:959-91.

23 Morrell G. Effect of structured preoperative teaching on anxiety levels of patients scheduled for cataract surgery. Insight 2001;26:4-9. 
24 Spina J Jr. The fear of cataract extraction: mental health aspects of a geriatric health problem. Clinical Gerontologist 1984;2:69-70.

25 O'Malley TP, Newmark TS, Rothman Ml, et al. Emotional aspects of cataract surgery. Int J Psychiatry Med 1989;19:85-9.

26 Morgan LW, Schwab IR. Informed consent in senile cataract extraction. Arch Ophthalmol 1986;104:42-5.
27 Wickremasinghe SS, Tranos PG, Sinclair N, et al. Visual perception during phacoemulsification cataract surgery under subtenons anaesthesia. Eye 2003;17:501-5.

28 Salmon P. The reduction of anxiety in surgical patients: an important nursing task or the medicalization of preparatory worry? Int J Nurs Stud 1993;30:323-30. 